\title{
Physiological evidence that emphysema is not a feature of byssinosis
}

\author{
D HONEYBOURNE, CAC PICKERING
}

From the Chest Unit, Wythenshawe Hospital, Manchester

\begin{abstract}
A group of women with byssinosis of grades 2 and 3 were seen consecutively over three years in an occupational outpatient clinic. Detailed lung function tests were performed and the results for smokers and non-smokers compared. One hundred and fifty three patients were seen and 50 of these were life time non-smokers, 35 smoked one to nine cigarettes a day, and 68 smoked 10 or more cigarettes a day. After correction for age the mean $F E V_{1}$ was found to be significantly lower $(p<0.01)$ in heavy smokers than in non-smokers. In a subgroup of 89 subjects who were able to perform the carbon monoxide gas transfer test significantly lower values were obtained for the carbon monoxide transfer factor (TLCO), ( $p<0.001)$, TLCO \% predicted $(p<0.001)$, and the transfer coefficient $(\mathrm{KCO})(\mathrm{p}<0.001)$ in the heavy smokers than in the non-smokers, despite the fact that the non-smokers had worked longer in the cotton mills $(\mathrm{p}<0.02)$. The mean TLCO was significantly lower than predicted in the heavy smokers $(p<0.001)$ but not in the non-smokers. A significant negative correlation was found between the number of cigarettes smoked per day and the TLCO $(\mathrm{p}<0.01)$, TLCO \% predicted $(\mathrm{p}<0.001)$, and KCO $(\mathrm{p}=0.005)$, but not with the number of years spent in the carding area. These results provide evidence supporting recent pathological observations that emphysema is probably due to concomitant cigarette smoking and is not itself a feature of byssinosis.
\end{abstract}

The diagnosis of byssinosis is made on the basis of a history of work related chest tightness or shortness of breath, initially on the first working day of the week (grades 1/2 and 1), which may later extend through the working week (grade 2) or even become permanent (grade 3). ${ }^{1}$ Most, if not all, patients with grade 2 or 3 byssinosis have functional evidence of chronic airflow obstruction. It has also been claimed that emphysema is a feature of these more severe cases. ${ }^{1}$ Recent pathological studies based on the postmortem findings in byssinotic lungs have, however, cast doubt on this, and it has been suggested that any emphysema present may be due to associated cigarette smoking rather than to textile dusts. ${ }^{23}$

No previous study has attempted to separate the effects of cigarette smoking from those of cotton dust on functional measurements, in particular the carbon monoxide transfer factor (TLCO) and transfer coefficient $(\mathrm{KCO})$. The latter is characteristically

Address for reprint requests: Dr D Honeybourne, MD, Dudley Road Hospital, Birmingham B18 7QH.

Accepted 2 September 1985 reduced with emphysema but not with "pure" chronic obstructive bronchitis without emphysema. ${ }^{45}$

\section{Methods}

One hundred and fifty three women with byssinosis were seen in an occupational chest disease outpatient clinic. They were assessed consecutively over a three year period by one physician. All had been previously accepted by the Pneumoconiosis Medical Panel as suffering from grade 2 or 3 byssinosis, according to the criteria of Schilling. ${ }^{1}$ They attended the clinic for an independent assessment of their disability, which included a detailed history, physical examination, and lung function testing. Eighty two men with byssinosis were also seen during this period but they have been excluded from this report because the great majority were smokers, whereas a more even distribution of smokers and non-smokers was found among the women.

Non-smokers were defined as subjects who denied ever having smoked a cigarette. Smokers were defined as those who had smoked cigarettes during the period when they were working in a cotton mill. Smokers 
Table 1 Details of group $A$

\begin{tabular}{|c|c|c|c|c|c|}
\hline & \multirow{2}{*}{$\begin{array}{l}\text { Height }(\mathrm{cm}) \\
(\text { mean }(S D))\end{array}$} & \multirow{2}{*}{$\begin{array}{l}\operatorname{Age}(y) \\
(\operatorname{mean}(S D))\end{array}$} & \multicolumn{3}{|c|}{ Years of exposure (mean (range)) } \\
\hline & & & Total in mills & Carding & Spinning \\
\hline $\begin{array}{l}\text { Heavy smokers } \\
\text { Light smokers } \\
\text { Non-smokers }\end{array}$ & $\begin{array}{l}158.1(6.7) \\
159.1(6.5) \\
157.6(7.2)\end{array}$ & $\begin{array}{c}* 56.3(9.3) \\
58.7(8.6) \\
* 61.8(10.8)\end{array}$ & $\begin{array}{r}* 29.2(5-45) \\
\$ 27.7(4-52) \\
\S * 34.8(5-54)\end{array}$ & $\begin{array}{l}18.0(0-45) \\
21.8(0-49) \\
24.5(0-54)\end{array}$ & $\begin{array}{r}11.3(0-43) \\
7.9(0-42) \\
10.3(0-45)\end{array}$ \\
\hline
\end{tabular}

Significant differences: $\S^{*} p<0.01$.

were further divided into those who had smoked an average of at least 10 cigarettes a day ("heavy" smokers) and those who had smoked fewer ("light" smokers). A comparison was made of the lung function of the non-smokers, those who had smoked 10 or more cigarettes a day, and those who had smoked one to nine cigarettes a day.

Age, height, and number of years spent in the carding and spinning processes were determined for each subject. Each was questioned at length about work related respiratory symptoms, and also about her current level of disability.

The following measurements were made: forced expiratory volume in one second $\left(\mathrm{FEV}_{1}\right)$ and vital capacity (VC) (taken as the best of three attempts), measured with a Gould-Godart water filled spirometer; TLCo, alveolar volume (VA), and Kco measured with PK Morgan Transfer Test Model C. The capillary haemoglobin concentration was measured and the TLCo value corrected to a normal value. The subjects did not smoke for at least an hour before the measurements were made. The maximum expiratory flow-volume curve was measured with an Ohio dry spirometer with a Bryans XY plotter to derive $\operatorname{Vmax}_{75}$ (that is, the flow rate with $25 \%$ of the vital capacity remaining in the lungs). Arterial blood gases were measured with a Radiometer BMS3 system. Predicted values were obtained from Cotes. ${ }^{6}$

Some subjects were unable to perform the carbon monoxide transfer test as they could not hold their breath for the required period. There were therefore three groups of both the smoking and the nonsmoking subjects. The A groups comprised all subjects who underwent spirometric testing, and each was subdivided into those who were unable to perform the TLCO and Kco tests (the B groups) and those who were able to perform these tests (the C groups).

As there were significant differences in both age and height between the smokers and the non-smokers all the lung function data were corrected for age and the FEV $_{1}$, VC, $\dot{V}_{\max _{75}}$, and TLCO were also corrected for height. ${ }^{6}$ The corrections were applied to the nonsmokers and to the light smokers (1-9 cigarettes/day) on the basis of the mean age and height of the three smoking groups of those who had smoked at least 10 cigarettes a day.

Workers who had worked only in the carding area and never in the spinning area were identified. In these workers the results of lung function tests for heavy smokers and for non-smokers were compared.

The results for the smokers and non-smokers were then analysed. The data were tested for normality and if this was present a two tailed $t$ test was performed; otherwise the Mann-Whitney U test was used.

The analyses of results for smokers and nonsmokers within each group were as follows: group A: comparison of spirometric values; group B: as for group A; group C: as for group A plus $\dot{\mathrm{V}} \max _{75}$, results of gas transfer tests, and arterial oxygen tension $\left(\mathrm{PaO}_{2}\right)$.

Correlation coefficients were also derived by combining the smoking and non-smoking subjects and comparing number of years of carding against TLCO, TLCo \% predicted, and KCO. A comparison was also made between the mean TLCO values of smokers and non-smokers and the means of the predicted values for the subjects. The standard deviation of the predicted values was $3.59 \mathrm{ml} \mathrm{min}^{-1} \mathrm{~mm} \mathrm{Hg}^{-1}$.

Table 2 Details of groups $B$ and $C$

\begin{tabular}{|c|c|c|c|c|c|}
\hline & \multirow{2}{*}{$\begin{array}{l}\text { Height }(\mathrm{cm}) \\
(\text { mean }(S D))\end{array}$} & \multirow{2}{*}{$\begin{array}{l}\text { Age }(y) \\
(\operatorname{mean}(S D))\end{array}$} & \multicolumn{3}{|c|}{ Years of exposure (mean (range)) } \\
\hline & & & Total in mills & Carding & Spinning \\
\hline \multicolumn{6}{|l|}{ Group B } \\
\hline Heavy smokers & $154.2(6.0)$ & $63.5(7.0)$ & $† 27.9(11-43)$ & $16.7(0-33)$ & $10.8(0-43)$ \\
\hline Non-smokers & $154.8(4.9)$ & $64.6(9.0)$ & $\dagger 35.1(24-47)$ & $25.6(0-47)$ & $9.5(0-43)$ \\
\hline \multicolumn{6}{|l|}{ Group C } \\
\hline Heavy smokers & $158.8(6.7)$ & $+55.0(9.1)$ & $+29.5(5-45)$ & $18.2(0-45)$ & $11.4(0-40)$ \\
\hline Non-smokers & $159.1(6.3)$ & $+60.2(11.5)$ & $+34.6(5-54)$ & $23.9(0-54)$ & $10.7(0-45)$ \\
\hline
\end{tabular}

$+\mathrm{p}<0.02 ; \ddagger \mathrm{p}<0.05$. 
Table 3 Mean (SD) spirometric results in group $A$

\begin{tabular}{|c|c|c|c|}
\hline & $\begin{array}{l}\text { Heavy smokers } \\
n=68\end{array}$ & $\begin{array}{l}\text { Light smokers } \\
n=32 \\
\text { (corrected) }\end{array}$ & $\begin{array}{l}\text { Non-smokers } \\
n=50 \\
\text { (corrected) }\end{array}$ \\
\hline $\begin{array}{l}\text { FEV }_{1} \text { (l) } \\
\text { FEV }_{1}(\% \text { pred) } \\
\text { Vital capacity (l) }_{\text {cacity }}\end{array}$ & $\begin{array}{l}* 1.49(0.56) \\
70.1(22.8) \\
\ddagger 2.15(0.56)\end{array}$ & $\begin{array}{c}1.55(0.52) \\
70.2(21.6) \\
2.20(0.57)\end{array}$ & $\begin{array}{l}* 1.76(0.47) \\
76.2(22.4) \\
\ddagger 2.41(0.66)\end{array}$ \\
\hline $\begin{array}{c}\text { (\% pred) } \\
\text { FEV }_{1} / \text { VC }(\%)\end{array}$ & $\begin{array}{l}69.9(16.3) \\
68.6(16.0)\end{array}$ & $\begin{array}{l}68.6(16.4) \\
69.1(12.3)\end{array}$ & $\begin{array}{l}69.6(18.1) \\
72.2(13.0)\end{array}$ \\
\hline
\end{tabular}

\section{Results}

Of the 153 women 50 were non-smokers, 35 smoked one to nine cigarettes a day, and 68 smoked 10 or more cigarettes a day. Lung function results are therefore based on the following groups:

Non-smokers

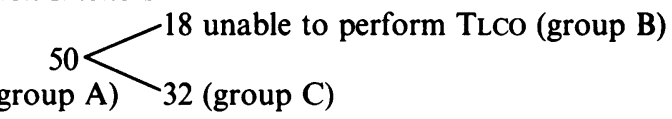

Light smokers

Heavy smokers

$$
\text { (group A) } 57 \text { (group C) }
$$

The mean number of cigarettes smoked per day by those who smoked 10 or more was 18.1 (range 10-50).

The non-smoking workers were significantly older than the heavy smokers in both group $A(p<0.01)$ and group $C(p<0.05)$. The non-smokers also had had significantly longer exposure to cotton dust

\begin{tabular}{|c|c|c|}
\hline & $\begin{array}{l}\text { Heavy smokers } \\
n=11\end{array}$ & $\begin{array}{l}\text { Non-smokers } \\
n=18 \\
\text { (corrected) }\end{array}$ \\
\hline $\begin{array}{l}\mathrm{FEV}_{1}(1) \\
\text { FEV }_{1}(\% \text { pred }) \\
\text { Vital capacity }(1) \\
\text { Vital capacity }(\% \text { pred })_{\mathrm{FEV}_{1} / \mathrm{VC}(\%)}(\%)\end{array}$ & $\begin{array}{l}\$ 0.94(0.35) \\
* 52.5(22.5) \\
* 1.51(0.40) \\
54.0(13.0) \\
62.0(17.0)\end{array}$ & $\begin{array}{l}\$ 1.66(0.52) \\
* 67.6(26.3) \\
* 2.16(0.61) \\
61.7(18.1) \\
70.7(14.8)\end{array}$ \\
\hline
\end{tabular}

Table 4 Mean (SD) spirometric results in group $B$

$\S \mathrm{p}<0.001 ;{ }^{*} \mathrm{p}<0.01$.

$$
\text { (group A) } 24 \text { (group C) }
$$

(tables 1 and 2). The corrected spirometric results of the three groups are shown in tables 3-5. After correction for age and height there was a significant difference between the $\mathrm{FEV}_{1}$ values of the heavy smokers and non-smokers in group $A(p<0.01)$ and group $\mathrm{C}(\mathrm{p}<0.05)$.

There were no significant differences in age or height between the light smokers and the heavy smokers or non-smokers. The spirometric values for the light smokers in groups $\mathrm{A}, \mathrm{B}$, and $\mathrm{C}$ were intermediate between the values for non-smokers and heavy smokers, with no significant differences between them.

As the main aim of the study was to compare Trco and $\mathrm{KCO}$ in the smokers and non-smokers, detailed analysis was confined to group C. Table 5 shows the values for $\dot{V}_{\max }{ }_{75}$ and $\mathrm{PaO}_{2}$ in group C. V́max (corrected for age and height) was significantly lower in the heavy smokers $(p<0.05)$. Table 6 shows the carbon monoxide transfer factor values for group $\mathrm{C}$ (corrected for age and height). The mean TLCo and KCO were significantly lower in the heavy smokers than in the non-smokers $(p<0.001)$. Moreover, the mean predicted TLCo for smokers was $22 \mathrm{ml} \mathrm{min}^{-1}$ $\mathrm{mm} \mathrm{Hg}^{-1}$ (SD 3.6), which is significantly higher $(p<0.001)$ than the observed mean TLCo of 19.0 (4.5). No such reduction was found in the nonsmoking group. The light smokers in group $\mathrm{C}$ had a significantly lower mean Kco than the non-smokers $(\mathrm{p}<0.02)$, but a significantly higher mean TLCO and

\begin{tabular}{|c|c|c|}
\hline & $\begin{array}{l}\text { Heavy smokers } \\
n=57\end{array}$ & $\begin{array}{l}\text { Non-smokers } \\
n=32 \\
\text { (corrected) }\end{array}$ \\
\hline 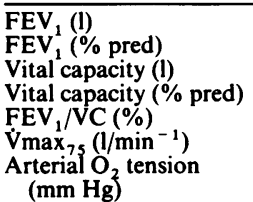 & $\begin{array}{c}+1.60(0.53) \\
73.5(21.4) \\
\ddagger 2.27(0.51) \\
72.9(15.2) \\
69.8(15.6) \\
+52.3(31.5) \\
74.2(6.4)\end{array}$ & $\begin{array}{c}+1.82(0.44) \\
81.0(18.5) \\
\ddagger 2.56(0.66) \\
74.1(16.8) \\
73.2(12.5) \\
+68.6(36.2) \\
75.1(8.1)\end{array}$ \\
\hline
\end{tabular}
Kco than the heavy smokers (table 6).

Table 7 shows the lung function results for those

\begin{tabular}{|c|c|c|c|}
\hline & $\begin{array}{l}\text { Heavy smokers } \\
n=57\end{array}$ & $\begin{array}{l}\text { Light smokers } \\
n=24 \\
\text { (corrected) }\end{array}$ & $\begin{array}{l}\text { Non-smokers } \\
n=32 \\
\text { (corrected) }\end{array}$ \\
\hline 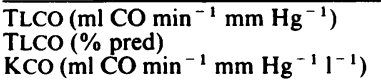 & $\begin{array}{l}\S+19.0(4.5) \\
\S \neq 86.1(20.3) \\
\S+4.98(1.20)\end{array}$ & $\begin{array}{l}+22.6(4.8) \\
* 98.8(21.1) \\
+* 5.51(0.98)\end{array}$ & $\begin{array}{c}\$ 22.9(4.4) \\
\S 104.0(18.7) \\
\S * 6.09(0.78)\end{array}$ \\
\hline
\end{tabular}

Table 5 Mean (SD) spirometric results in group C

Table 6 Mean (SD) values for carbon monoxide transfer factor (TLCO) and transfer coefficient (KCO)

$\$ p<0.001 ; \mathrm{p}<0.01 ;{ }^{*} \mathrm{p}<0.02 ; \mathrm{p}<0.05$.

To convert TLCo and Kco to SI units divide by 3 . 
Table 7 Lung function test results (means and SD) for carders only

\begin{tabular}{|c|c|c|}
\hline & $\begin{array}{l}\text { Heavy smokers } \\
n=46\end{array}$ & $\begin{array}{l}\text { Non-smokers } \\
n=50 \\
\text { (corrected) }\end{array}$ \\
\hline $\begin{array}{l}\text { Age }(y) \\
\text { Height }(\mathrm{cm}) \\
\text { Years spent carding } \\
\quad \text { (range in parentheses) }\end{array}$ & $\begin{array}{c}* 58.7(9.8) \\
158.1(6.3) \\
30.3(5-45)\end{array}$ & $\begin{array}{r}* 64.5(9.4) \\
158.4(6.5) \\
34.6(3-54)\end{array}$ \\
\hline $\begin{array}{l}\text { FEV }_{1}(1) \\
\text { FEV }_{1}(\% \text { pred) } \\
\text { Vital capacity (l) } \\
\text { Vital capacity ( } \% \text { pred) } \text { FEV }_{1} / \text { VC } \% \\
\text { TLCO ( } \% \text { pred) }\end{array}$ & $\begin{array}{c}1.43(0.53) \\
69.9(20.4) \\
2.08(0.56) \\
67.9(16.0) \\
68.1(14.5) \\
* 87.5(21.1) \\
(n=39)\end{array}$ & $\begin{array}{c}1.57(0.55) \\
75.2(24.8) \\
2.14(0.61) \\
68.1(16.9) \\
71.4(15.5) \\
* 100.4(17.4) \\
(n=34)\end{array}$ \\
\hline
\end{tabular}

${ }^{*} \mathrm{p}<0.01$

workers who had worked only in the carding area and who were heavy smokers or non-smokers. There was a trend for lower spirometric values among the heavy smokers but this did not reach significance even after correction for age and height differences. The heavy smokers were, however, significantly younger and had a lower TLCO \% predicted than the non-smokers.

Within group $\mathrm{C}$ average daily cigarette intake showed significant inverse correlations with TLCO, $(r$ $=-0.29, \mathrm{p}<0.01) ;$ TLCO $\%$ predicted $(\mathrm{r}=-0.36$, $p<0.005)$; and KCO $(r=-0.36, p=0.005)$. No significant correlation was found between years of carding and TLCO, TLCO \% predicted, or KCO.

\section{Discussion}

All subjects in this study had spent many years working in the dustiest parts of cotton mills-that is, the carding and spinning areas. The mean number of years spent carding was slightly lower in the heavy smoking groups but the mean number of years spent in spinning was similar. Most of the relevant cotton mills at that time were processing medium or coarse cotton. These groups of subjects would therefore be expected to contain many of those most severely affected with byssinosis who had worked in local mills. Although some selection bias will have inevitably occurred before they were seen in our clinic-for example due to migration away from the localitynevertheless a within group comparison of smokers and non-smokers is valid since there was no known external factor favouring smokers or non-smokers attending the clinic for assessment.

Subjects in all of the three groups showed the well recognised reduction in $\mathrm{FEV}_{1}$ and $\mathrm{VC}$. A recent study has shown a higher prevalence of both obstructive and restrictive abnormalities of lung function in cotton textile workers than in control subjects. ${ }^{7}$ The mean $\mathrm{FEV}_{1}$ of cotton workers is known to become progressively lower as the grade of byssinosis increases. ${ }^{8}$ The decline in $\mathrm{FEV}_{1}$ in cotton workers is greatest in those who have worked longest in the mill ${ }^{9}$; our subjects had worked for a mean of 31.6 years in the mills. Our results for non-smoking women show a mean $\mathrm{FEV}_{1}$ (as percentage of predicted values) of $76 \%$ in group $A, 68 \%$ in group $B$, and $81 \%$ in group $C$. These results were obtained in byssinotic subjects of grades 2 and 3 and therefore are lower than those found in another study of nonsmoking female workers with 16 years' exposure to cotton dust, who had byssinosis of grades $1 / 2$ and 2 with a mean $\mathrm{FEV}_{1}$ of $90 \%$ predicted. ${ }^{9}$

The $\mathrm{FEV}_{1}$ (percentage of predicted) values were consistently lower in heavy smokers than in nonsmokers, but this trend did not reach statistical significance except in group B. It is, of course, impossible to estimate in retrospect the dust concentrations to which the individuals were exposed during their work. Possibly the smokers had less exposure than the non-smokers-smokers are known to show a tendency to move away from dusty areas during their period of employment in the mills, ${ }^{1011}$ and this might account for the relatively small differences between them in our study.

The overall pattern of reduction in spirometric values in these women is therefore very similar to that found in previous studies, with greater impairment in smokers than in non-smokers. As would be expected, the mean values of $F E V_{1}$ were lower in group $B$ than in groups $A$ or $C$ because group $B$ subjects were those who were unable to perform the single breath manoeuvre owing to their inability to hold their breath for 10 seconds. Within group B the heavy smokers had significantly lower values of $\mathrm{FEV}_{1}$ and $\mathrm{VC}$, and the results in group $\mathrm{C}$ were not therefore due to a higher proportion of non-smokers with very poor lung function in group $\mathbf{B}$.

The most striking differences between group $\mathrm{C}$ smokers and non-smokers were in the carbon monoxide transfer factor. The mean TLCo was normal for the non-smokers but was significantly reduced at $86.1 \%$ of the predicted value in the heavy smokers. The mean TLCo was also significantly lower in absolute terms in the heavy smokers and the mean Kco was significantly lower in both the heavy and the light smokers than in the non-smokers. This would be consistent with emphysematous changes occurring in the smoking but not the non-smoking subjects. No other study has assessed differences in carbon monoxide transfer between smokers and non-smokers with byssinosis. One study ${ }^{12}$ looked at the acute effects of cotton dust on TLCo and found no change. Another study ${ }^{13}$ investigated lung static recoil measurements in hemp workers and found that the $F E V_{1}$ did not correlate with recoil pressure at TLC, whereas $\dot{V} \max _{50}$ did; the authors interpreted this as consistent 
with loss of parenchymal structure of the lungs in chronic byssinosis. An alterntive explanation of their findings, however, is that smoking may have been the causative factor as 17 of their 23 subjects were smokers. This study therefore did not separate the effects of textile dust from cigarette smoke and a relationship between emphysema and byssinosis cannot be inferred.

It is known that cigarette smoking may cause a small reduction in the measured TLCo by a "back pressure" effect of carbon monoxide in the blood. One study ${ }^{14}$ has shown that an average smoker (10-20 cigarettes per day) has an arterial carbon monoxide tension of $8.96 \mathrm{~mm} \mathrm{Hg}(1.19 \mathrm{kPa})$, and we can calculate that an underestimation of TLCO due to back pressure effects would be, at the most $6 \%$. If this correction is applied to the results in table 6 then the significant differences in TLCO, TLCO $\%$ predicted, and $\mathrm{Kco}$ between the heavy smokers and the nonsmokers still remain $(\mathrm{p}<0.01, \mathrm{p}<0.01, \mathrm{p}<0.001$, respectively). Another study ${ }^{15}$ included a subgroup of women aged 45 years or more and their TLCO and KCO were slightly higher in the non-smokers than in smokers of up to 24 cigarettes per day but the differences were not significant.

In this study no significant differences were found in the spirometric results between heavy smokers and non-smokers among workers who had worked only in the carding area, although a consistent trend of lower values was seen in the heavy smokers (table 7). Although no dust measurements are available in this study, dust levels in carding areas are known to be consistently higher than those in spinning areas and these workers are likely to have been exposed to the highest concentration of cotton dust. If a large interaction between the effects of cotton dust and cigarette smoke on the lungs occurred then one would expect significantly lower spirometric values in the heavy smokers than in the non-smokers. The fact that this was not observed suggests either that no interaction occurs or that it was too small to be detected by the design of our study.

There have been two comprehensive postmortem studies on byssinotic lungs. One comprised an analysis of the lungs of 49 cotton workers, of whom 36 had been smokers; 16 of the smokers had centrilobular emphysema but only one of the nonsmoking group. ${ }^{16}$ The authors concluded that centrilobular emphysema was not significantly associated with a history of employment in the cotton industry but was significantly related to cigarette smoking and age. They were unable to state what proportion of these workers had suffered from byssinosis. Another study $^{2}$ found that 27 of 42 patients with byssinosis had no evidence of emphysema at necropsy. No details of smoking were given in that publication but a more recent paper has added these details. ${ }^{17}$ Emphysema was again much commoner in smokers than in non-smokers with byssinosis, although the numbers were small. Hence in pathological studies non-smoking cotton workers have not been shown to have more emphysema than would be expected when compared with a group of non-smokers from a different occupation. ${ }^{18}$

In this study of women with advanced byssinosis we have found functional evidence that emphysema is related to concomitant cigarette smoking rather than to cotton dust exposure. Two recent publications ${ }^{1819}$ have questioned whether long exposure to cotton dust leads to the development of emphysema. Our study suggests that it does not.

We thank Mr EB Faragher for his help with the statistical analyses.

\section{References}

1 Schilling RSF, Vigliani EC, Lammers B, Valic F, Gilson JC. In: Bouhuys A, ed. Proceedings of the XIVth international congress on occupational health, Madrid 1963. Vol 2. series No. 62 Amsterdam: Exerpta Medica Foundation, 1964:137-45. (International congress series No.62.)

2 Edwards C, McCartney J, Rooke G, Ward F. The pathology of the lung in byssinosis. Thorax 1975;30: 612-23.

3 Pratt PC, Vollmer RT, Miller JA. Prevalence and severity of morphologic emphysema and bronchitis in nontextile and cotton textile workers. Chest 1980;77, suppl:323-5.

4 Fletcher CM, Hugh-Jones P, McNicol MW, Pride NB. The diagnosis of pulmonary emphysema in the presence of chronic bronchitis. $Q J$ Med 1963;32:33-49.

5 Gonzales E, Weill H, Ziskind MM, Georges RB. The value of single breath diffusing capacity in separating chronic bronchitis and emphysema. Dis Chest 1968;53:229-38.

6 Cotes J. Lung function: principles and application in medicine. 4th ed. Oxford: Blackwell Scientific Publications, 1979.

7 Schachter EN, Maunder LR, Beck GJ. The pattern of lung abnormalities in cotton textile workers. Am Rev Respir Dis 1984;129:523-7.

8 Merchant JA, Halprin GM, Hudson AR, et al. Evaluation before and after exposure - the pattern of physiological response to cotton dust. Ann NY Acad Sci 1974;221:38-43.

9 Zuskin E, Valic F. Respiratory symptoms and ventilatory function changes in relation to length of exposure to cotton dust. Thorax 1972;27:454-8.

10 Roach SA, Schilling RSF. A clinical and environmental study of byssinosis in the Lancashire cotton industry. $\mathrm{Br}$ $J$ Ind Med 1960;17:1-9.

11 Gandevia B, Milne J. Ventilatory capacity changes on exposure to cotton dust and their relevance to byssinosis in Australia. Br J Ind Med 1965;22:295-304.

12 Zuskin E, Valic F, Bouhuys A. Byssinosis and airway responses due to exposure to textile dust. Lung 
1976;154:17-24.

13 Guyatt AR, Douglas JS, Zuskin E, Bouhuys A. Lung static recoil and airway obstruction in hemp workers with byssinosis. Am Rev Respir Dis 1973;108:1111-5.

14 Rees PJ, Chilvers C, Clark TJH. Evaluation of methods used to estimate inhaled dose of carbon monoxide. Thorax 1980;35:47-51.

15 Van Ganse WF, Ferris Jr BG, Cotes JE. Cigarette smoking and pulmonary diffusing capacity (transfer factor). Am Rev Respir Dis 1972;105:30-41.

16 Pratt PC, Vollmer RT, Miller JA. Epidemiology of pulmonary lesions in non-textile and cotton textile workers, a retrospective autopsy analysis. Arch Environ Health 1980;35:133-8.

17 Rooke GB. The pathology of byssinosis. Chest 1981; 79:675-715.

18 Morgan WKC, Vesterlund J, Burrell R, Gee JBL, Willoughby WF. Byssinosis: some unanswered questions. Am Rev Respir Dis 1982;126:354-7.

19 Honeybourne D, Wales DS, Watson A, Lee WR, Sagar BF. Byssinosis - causative agent and clinical aspects. Manchester: Shirley Institute Publications (S43) 1982:70-4. 